\title{
Effect of natural and synthetic surfactants on crude oil biodegradation by indigenous strains
}

Wei Tian ${ }^{\mathrm{a}}$, Jun Yao ${ }^{\mathrm{a} *}$, Ruiping Liu ${ }^{\mathrm{a}}$, Mijia Zhua ${ }^{\mathrm{a}}$, Fei Wang ${ }^{\mathrm{a}}$, Xiaoying Wu $\mathrm{Wu}^{\mathrm{a}}$, Haijun Liu ${ }^{\text {b** }}$

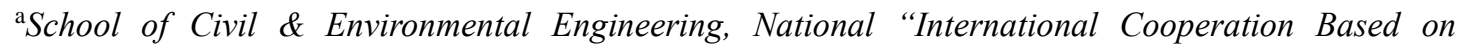
Environment and Energy”, University of Science and Technology Beijing, Beijing, 100083, PR China ${ }^{b}$ School of Resources and Environment, Anqing Normal University, 1318 Jixian North Road, Anqing 246133, PR China

\section{Abstract}

Hydrocarbon pollution is a worldwide problem. In this study, five surfactants containing SDS,

LAS, Brij 30, Tween 80 and biosurfactant were used to evaluate their effect on crude oil biodegradation. Hydrocarbon degrading bacteria were isolated from oil production water. The biosurfactant used was a kind of cyclic lipopeptide produced by Bacillus subtilis strain WU-3. Solubilization test showed all the surfactants could apparently increase the water solubility of crude oil. The microbial adhesion to the hydrocarbon (MATH) test showed surfactants could change cell surface hydrophobicity $(\mathrm{CSH})$ of microbiota, depending on their species and concentrations. Microcalorimetric experiments revealed these surfactants exhibited toxicity to microorganisms at high concentrations (above $1 \mathrm{CMC}$ ), except for SDS which showed low antibacterial activity. Surfactant supplementation (about 0.1 and $0.2 \mathrm{CMC}$ ) could improve degradation rate of crude oil slightly, while high surfactant concentration (above 1 CMC) may decrease the degradation rate from $50.5 \%$ to $28.9 \%$. Those findings of this work could provide guidance for the application of surfactants in bioremediation of oil pollution.

Keywords: Biosurfactant; Synthetic surfactant; Toxicity; Hydrophobicity; Solubilization

\section{Introduction}

As a result of rapid industrial development, the threat of petroleum contaminations has

${ }^{*}$ Corresponding author. Tel./fax: +86 1062333305.

** Corresponding author. Tel./fax:+86 5565500130

E-mail addresses: yaojun@ustb.edu.cn (J. Yao), liuhj@aqtc.edu.cn (H.J. Liu) 
inevitably increased. The release of hydrocarbon pollutants has caused extensive contamination of surface soils, groundwater, seas and ocean. And this resulted in ecosystem damage through spillages and leakage from underground tanks, steamers, unplugging of oil wells, and abandoned oil refinery sites (Janbandhu and Fulekar, 2011; Prince et al., 2013). Chemical, physical, and biological treatments have been used to remove these hydrocarbon pollutants from the environment. Owing to its environmentally friendly, cost-effective, and efficient advantage comparied with physicochemical treatments, bioremediation has gained increasing interest (Bao et al., 2012; Ferradji et al., 2014; Millioli et al., 2009). Some studies have been reported to use bioremediation successfully for spilled oil (Greenwood et al., 2009; Hii et al., 2009).

Numerous aerobic and anaerobic microorganisms were isolated such as algae, bacteria, fungi and yeasts, which were capable of utilizing petroleum compounds as a sole carbon source (Mnif et al., 2014). Crude oil is a complex mixture, and complete oil degradation commonly requires synergistic actions of different microbial species or strains (El-Tarrs et al., 2012). Kumar et al.(2014) reported that pure cultures were able to utilize spent engine oil, but none of the cultures was more efficient than the mixed bacterial consortium, and this result was in agreement with the finding of Díaz et al. (2000) who reported the combination of different cultures producing a synergistic effect and thereby increasing the biodegradation of crude oil.

The bioavailability of hydrocarbon compounds is reduced significantly due to their limited water solubility, which adversely affects their biodegradation in the environment (Megharaj et al., 2011; Millioli et al., 2009). Adding surfactant is a feasible approach to enhance the 
bioavailability, solubilization, and biodegradation of hydrophobic pollutants. Surfactants can improve hydrocarbon utilization through emulsifications as well as adhesion on microbial cell surfaces (Singh et al., 2007). Biosurfactants have been gaining increasing interest due to their lower toxicity, higher environmental compatibility, biodegradability and stability advantages over chemical surfactants (Benincasa et al., 2010; Thavasi et al., 2011). Thus, both effect of natural and synthetic surfactants should be studied on crude oil biodegradation.

Studies showed surfactants could increase hydrocarbon bioavailability by hydrocarbon solubizization or the strengthen of cell surface hydrophobicity (CSH) (Luning Prak et al., 2000; Mulligan, 2005; Obuekwe et al., 2009), which lead to enhance hydrocarbon utilization. However, surfactants are not always beneficial for the degradation system, and it may promote, inhibit or have no effect on hydrocarbon biodegradation (Paria, 2008; Urum and Pekdemir, 2004). There are many reasons responsible for the negative impact, as surfactants may lead to a drastic decrease of the $\mathrm{CSH}$, and usually exhibit toxicity when used at a high concentration, but occasionally utilize as a preferential carbon source (Yu et al., 2007). Furthermore, hydrocarbon biodegradation may be suppressed owing to its unavailability to microbial cells entrapped in surfactant micelles (Chrzanowski et al., 2011; Wang, 2011).

There are many studies about effect of surfactants on hydrocarbon biodegradation, but few of them focus on hydrocarbon biodegradation influenced by surfactants from bacteria in oil production water. This study aims to investigate the overall effect of one biosurfactant and four synthetic surfactants on indigenous microbial community for crude oil biodegradation. The effect of surfactants were evaluated on crude oil solubilization, CSH alteration, and bacterial growth. 


\section{Materials and methods}

\subsection{Sampling}

Oil production water samples were collected using sterile glass bottles from the Gangxi region in the Dagang oil field, China. The temperature of sampled oil reservoirs ranges from 52 to $65{ }^{\circ} \mathrm{C}$, and the depth is from 948 to $957 \mathrm{~m}$. Samples were stored at $4{ }^{\circ} \mathrm{C}$ in the laboratory for further use (Cai et al., 2015).

\subsection{Microorganisms and culture conditions}

The microbial consortium used throughout this study was obtained from oil production water. Bacterial 16S rRNA clone library analysis revealed that microbes in production water were mainly $\alpha$-proteobacteria, and culturable microorganisms included genus Sphingomonas and genus Pseudomonas. The clone analysis also indicated that archaea in production water were mainly Methanosarcina (unpublished results). A number of studies demonstrated that genus Sphingomonas was one of the dominant species in the microbial communities of PAH-contaminated soil and water samples (Brito et al., 2006; Saul et al., 2005; Shokrollahzadeh et al., 2008). And genus Pseudomonas was known to have an important potential to degrade PAHs and alkanes (Molina et al., 2009). An enrichment procedure was performed in $150 \mathrm{ml}$ Erlenmeyer flasks containing $50 \mathrm{ml}$ mineral salts medium (MSM) and 1\% w/v crude oil as the only carbon source. The MSM medium contained $\mathrm{NaCl} 10 \mathrm{~g}, \mathrm{NH}_{4} \mathrm{Cl} 0.5$ $\mathrm{g}, \mathrm{KH}_{2} \mathrm{PO}_{4} 0.5 \mathrm{~g}, \mathrm{~K}_{2} \mathrm{HPO}_{4} 1.0 \mathrm{~g}, \mathrm{MgSO}_{4} 0.5 \mathrm{~g}, \mathrm{KCl} 0.1 \mathrm{~g}, \mathrm{CaCl}_{2} 0.02 \mathrm{~g}$ and $\mathrm{FeCl} \cdot 4 \mathrm{H}_{2} \mathrm{O} 0.02 \mathrm{~g}$ in $1000 \mathrm{ml}$ deionized water, and the $\mathrm{pH}$ was adjusted to 7.0 with $1.0 \mathrm{M} \mathrm{NaOH} / \mathrm{HCl}$ before sterilization under $121{ }^{\circ} \mathrm{C}$ for $30 \mathrm{~min}$. The flasks were incubated at $30{ }^{\circ} \mathrm{C}$ and $160 \mathrm{rpm}$ on a rotary shaker for 7 days. The culture was enriched by 4 consecutive inoculations of $5 \mathrm{ml}$ 
inoculum to $50 \mathrm{ml}$ fresh sterilized MSM medium. Cells were harvested by centrifugation and washed three times with saline solution. Then, cells obtained from the plates were stored in LB medium that contained $10 \mathrm{~g}$ of $\mathrm{NaCl}, 10 \mathrm{~g}$ of tryptone and $5.0 \mathrm{~g}$ of yeast extract in 1000 $\mathrm{ml}$ deionized water at $\mathrm{pH} 7.0$ with $15 \%$ of glycerol at $-80{ }^{\circ} \mathrm{C}$ for later inoculation (Liu et al., 2014).

To prepare the seed culture, $1 \mathrm{ml}$ bacterial stock culture aforementioned was incubated in LB medium for 24 hours. The obtained cells were washed with the potassium phosphate buffer (pH 7.2) and centrifuged again at $5000 \mathrm{~g}$ for $15 \mathrm{~min}$ at $4{ }^{\circ} \mathrm{C}$. The process repeated 3 times and then bacteria resuspended in potassium phosphate buffer to measure the optical density at $600 \mathrm{~nm}$ by spectrophotometer (Shimadzu UV-1800,Tokyo, Japan). The final bacteria solution was ready for the crude oil biodegradation.

\subsection{Surfactants}

In this study, two anionicsynthetic surfactants i.e. sodium dodecyl sulfate (SDS, chemically pure, formula $\mathrm{C}_{12} \mathrm{H}_{25} \mathrm{NaO}_{4} \mathrm{~S}$, molecular weight 288.38) and sodium dodecyl benzene sulfonate (SDBS/LAS, analytical reagent, formula $\mathrm{C}_{18} \mathrm{H}_{29} \mathrm{NaO}_{3} \mathrm{~S}$, molecular weight 348.48), two non-ionic synthetic surfactants i.e. Tween 80 (chemically pure, density (at $20{ }^{\circ} \mathrm{C}$ ) $1.05 \sim 1.10$ g/ml) and Brij 30 (high grade purity, formula $\mathrm{C}_{32} \mathrm{H}_{66} \mathrm{O}_{11}$, molecular weight 626.85), and a biosurfactant were used. The critical micelle concentration (CMC) of surfactants was determined with a JYW-200B tension meter (Chengde, China) using the ring method (Abouseoud et al., 2008) at about $25{ }^{\circ} \mathrm{C}$.

\subsubsection{Extraction and characterization of biosurfactant}

The biosurfactant was produced by Bacillus subtilis strain WU-3 (accession number 
KF894965 in the Genbank), which was previously isolated in our laboratory. The strain WU-3 was inoculated in the production medium containing peptone $10 \mathrm{~g}$, glucose $15 \mathrm{~g}, \mathrm{MgSO}_{4} 0.4 \mathrm{~g}$, $\mathrm{NH}_{4} \mathrm{Cl} 1.07 \mathrm{~g}, \mathrm{KCl} 1.49 \mathrm{~g}$, Tris- $\mathrm{HCl} 18.9 \mathrm{~g}$ per liter and incubated at $30^{\circ} \mathrm{C}$, and $160 \mathrm{rpm}$ for $72 \mathrm{~h}$. The extraction and purification procedure of the biosurfactant was carried out as described by Chandankere et al. (2013). Fourier transform infrared spectroscopy (FT-IR) analysis was conducted to identify the structural groups of the biosurfactant. $1.0 \mathrm{mg}$ of isolated biosurfactant was powdered with $1.0 \mathrm{~g}$ of $\mathrm{KBr}$, and then pressed under $7500 \mathrm{~kg}$ for $30 \mathrm{~s}$ to result a translucent KBr pellet. FT-IR spectrum was recorded on a Nexus 670 system (ThermoNicolet, USA) within the range of $4000-400 \mathrm{~cm}^{-1}$ wave number. All datas were corrected with background spectrum.

\subsection{Crude oil solubilization assay}

Procedures for solubility determination were described as follows: $100 \mathrm{ml}$ sterilized surfactant solution with various concentrations ( 0.1 times, 0.2 times, 0.5 times, 1 times and 2 times of CMC) was poured into $250 \mathrm{ml}$ Erlenmeyer flasks, and $0.5 \%$ w/v crude oil was also added into each flask. Flasks were sealed with a cork to prevent any loss from solution and incubated in a vertical position for $48 \mathrm{~h}$ at $30{ }^{\circ} \mathrm{C}$ with a shaking of $200 \mathrm{rpm}$ in dark. Preliminary experiment showed that 48 hours was sufficient to reach the solubilization equilibrium. For the solubilization analysis, the solution was transferred to a separating funnel to keep balance for $1 \mathrm{~h}$. Then $50 \mathrm{ml}$ bottom aqueous phase was transferred to a clean separating funnel, and a few drops of sulfuric acid (1:1) was added in to demulsify the solution. The crude oil in solution was extracted by $10 \mathrm{ml}$ hexane for 2 times. Hexane phases were combined, and then passed through anhydrous sodium sulfate to remove moisture. The solution was placed in a $25 \mathrm{ml}$ volumetric flask, and hexane was added in until the lower liquid level reached the scale line. 
Concentration of crude oil in the hexane extract was measured spectrophotometrically at 227 nm. Experiments were performed in triplicates, while control experiments were also conducted in parallel without biosurfactant in the assay sample.

\subsection{Cell surface hydrophobicity}

In order to investigate the cell surface hydrophobicity $(\mathrm{CSH})$ of the microbial community, microbial adhesion to the hydrocarbon (MATH) method was applied as described by Rosenberg et al.(1980). Microbial community was grown on $0.5 \% \mathrm{w} / \mathrm{v}$ crude oil in MSM medium with surfactants at different concentrations such as 0.1 times, 0.2 times, 0.5 times, 1 times and 2 times of CMC). After 7 days, cells were centrifuged at $10000 \times \mathrm{g}$, and washed twice with phosphate urea magnesium (PUM) buffer (19.7 $\mathrm{g} \mathrm{K}_{2} \mathrm{HPO}_{4}, 7.26 \mathrm{~g} \mathrm{KH}_{2} \mathrm{PO}_{4}, 1.8 \mathrm{~g} \mathrm{H}_{2} \mathrm{NCONH}_{2}$, and $0.2 \mathrm{~g}$ $\mathrm{MgSO}_{4} \cdot 7 \mathrm{H}_{2} \mathrm{O}$ per liter) and suspended to fit an optical density of ca. $1.0\left(A_{0}\right)$. Next, $1.5 \mathrm{ml}$ of xylene was added to $4 \mathrm{ml}$ of the cell suspension, and vortexed for $2 \mathrm{~min}$. After phase separation (15 min), theoptical density of the aqueous phase was measured $\left(A_{1}\right)$. Cell surface hydrophobicity was calculated as $\left[\left(A_{0}-A_{1}\right) / A_{0}\right] \times 100 \%$. Furthermore, in order to determine the effect of surfactant solutions to CSH of microbial community without crude oil supplemented, microorganisms cells in exponential phase in LB broth were harvested through centrifugation, then aliquots of cells resuspended in surfactant solutions with different concentrations as above mentioned. The system was cultivated on a shaker for enough time until the equilibrium appeared, then the CSH value was determined. Control experiments were also run in parallel with no surfactant supplemented. Each experiment was repeated three times, and the values of cell hydrophobicity were calculated as a mean value out of three flasks.

\subsection{Growth inhibition of microorganisms by surfactants}


Microcalorimetric measurement was conducted to determine the growth inhibition effect of surfactants on microorganisms. And the experiment was operated on a TAMIII multi-channel microcalorimeter (TA instruments, USA), which can measure the heat flow rate of microbial activity. Experiments were carried out using the procedure described by Wang et al. (2009). The thermal effect was obtained by using $4.0 \mathrm{~mL}$ of stainless steel ampoules, which were hermetically closed by Teflon sealing discs to control the evaporation and energy loss (Critter et al., 2001). The experiment temperature was at $28{ }^{\circ} \mathrm{C}$. All experiments were performed in ampoules containing $2.0 \mathrm{ml} \mathrm{LB}$ culture medium incubated with $100 \mu \mathrm{l}$ bacteria suspension and different doses of surfactants ( 0.1 times, 0.2 times, 0.5 times, 1 times and 2 times of CMC). The thermal effect associated with nutrient degradation was recorded by a detector and the metabolic parameters were then calculated from the power-time curves.

\subsection{Crude oil biodegradation assay}

The effect of one biosurfactant and four synthetic surfactants on crude oil biodegradation were tested. Experiments were carried out in $250 \mathrm{ml}$ flasks containing $100 \mathrm{ml}$ of mineral salts medium, supplemented with $0.5 \%(\mathrm{w} / \mathrm{v})$ crude-oil. Those five surfactants were added to the flask cultures at five different concentrations ( 0.1 times, 0.2 times, 0.5 times, 1 times and 2 times of CMC). 5\% $(\mathrm{v} / \mathrm{v})$ seed culture as mentioned was inoculated into flask cultures. All the flasks were incubated at $30{ }^{\circ} \mathrm{C}$, shaken at $160 \mathrm{rpm}$ for 10 days. Un-inoculated flasks were served as control. After the biodegradation process, the crude oil extraction procedure was conducted as described by Varjani et al.(2015). The solvent was allowed to evaporate and the total biodegradation rate was determined gravimetrically using the following formula: Biodegradation $(\%)=[(W I-W C) / W I]$ $\times 100$, where $W I$ is the weight of the residual oil in control and $W C$ is the weight of the fraction in 
the culture. Each experiment was repeated three times and those results were expressed as the mean and standard deviation of three in dependent measurements.

\subsection{Gas chromatography-mass spectrometer (GC-MS) analysis of residual oil}

The extracted residual oil was subjected to gas chromatography-mass spectrometer (GC-MS) analysis, and the procedure was described as Cai et al., 2015. GC-MS analysis was performed using a GCMS-QP2010 SE gas chromatograph-mass spectrometer (SHIMADZU), fitted with a acapillary column (RESTEK, USA) RXI-5 $\mathrm{ms}(30 \mathrm{~m} \times 0.25 \mathrm{~mm}$ i.d.,0.25 $\mu \mathrm{m}$ film). The carrier gas was $\mathrm{He}$ at $1.2 \mathrm{ml} / \mathrm{min}$, and the injection temperature was at $280{ }^{\circ} \mathrm{C}$. The temperature program was: $60{ }^{\circ} \mathrm{C}$ (hold $1 \mathrm{~min}$ ) to $150{ }^{\circ} \mathrm{C}$ at $15{ }^{\circ} \mathrm{C} / \mathrm{min}$ and then to $320{ }^{\circ} \mathrm{C}$ (hold $10 \mathrm{~min}$ ) at $6{ }^{\circ} \mathrm{C} / \mathrm{min}$.

\subsection{Statistical analyses}

Growth rate constant $(k)$ was calculated in triplicate, and the other analysis were performed in triplicate. Most values were presented as the mean \pm standard deviation (SD). Statistical analysis were performed with SPSS Version 21 using ANOVA analysis. Differences were considered significant at $\mathrm{p}<0.05$.

\section{Results and discussion}

\section{1 characterization of the produced biosurfactant}

The biosurfactant produced by Bacillus subtilis WU-3 was a pale yellow powder. The IR spectra of the biosurfactant was presented in Fig.1. The broad peak located at $3410 \mathrm{~cm}^{-1}$ was expected to be intermolecular stretching vibration of $\mathrm{N}-\mathrm{H}$ bond, indicating the presence of $\mathrm{NH}$ group. Strong absorption band at $1652.30 \mathrm{~cm}^{-1}$ indicated that the molecule contained a peptide bond, suggesting the hydrophilic group of the biosurfactant is a peptide chain. Two adsorption peaks at $2960 \sim 2850 \mathrm{~cm}^{-1}$ and $1409.60 \mathrm{~cm}^{-1}$ on the spectra was $\mathrm{C}-\mathrm{H}$ stretching of fatty acid family, 
indicating hydrophobic groups of the biosurfactant is fatty acid molecules. The adsorption at $1077.33 \mathrm{~cm}^{-1}$ was stretching vibration of -C-O-C- bond, indicating the presence of a cyclic lactone structure in the molecule (Najafi et al., 2010). The biosurfactant was tentatively characterized as cyclic lipopeptide molecules. Mukherjee (2007) reported that two Bacillus subtilis strains (DM-03 and DM-04), isolated from two extremely different habitats, were efficient producers of cyclic lipopeptide (CLP) biosurfactants. The biosurfactant produced by Bacillus subtilis WU-3is denoted as BS.

Results revealed that the CMC value of BS, SDS, LAS, Brij 30 and Tween 80 was 100mg/l, $600 \mathrm{mg} / \mathrm{l}, 4000 \mathrm{mg} / \mathrm{l}, 80 \mathrm{mg} / \mathrm{l}$ and $500 \mathrm{mg} / \mathrm{l}$, respectively. CMC is a significant parameter considered for the surfactant application in bioremediation, as it indicates the relative concentration of surfactant at which improvement in biodegradation can be observed (Sajna et al., 2015). Thus, surfactant concentration used in this study were both above and below CMC.

The stability of the BS was also tested to check if it is promising in different environmental applications. Results showed that $\mathrm{BS}$ was active at temperature ranging from $15 \sim 80{ }^{\circ} \mathrm{C}, \mathrm{pH}$ ranging from $4 \sim 12$ and salinity ranging from $2 \% \sim 12 \%$ (w/v) (data not shown here). The thermo-stability of other biosurfactants also had been reported in prvious studies (Mukherjee, 2007; Abdel-Mawgoud et al., 2008; Ghribi et al., 2012). Pathak and Keharia (2014) reported that cyclic lipopeptide biosurfactant produced by Bacillus subtilis $\mathrm{K} 1$ was stable at $100{ }^{\circ} \mathrm{C}$ for $2 \mathrm{~h}$, over a $\mathrm{pH}$ range of 6-12 and over an $\mathrm{NaCl}$ concentration up to $10 \%(\mathrm{w} / \mathrm{v})$. According to Sakthipriya et al. (2015), biosurfactant produced by Bacillus subtilis YB7 was able to withstand higher temperature (up to $120^{\circ} \mathrm{C}$ ), salinity (up to $10 \%$, w/v), and $\mathrm{pH}$ (above 8 ). BS's low activity at lower $\mathrm{pH}(2 \sim 4)$ might due to its precipitation, which was consistent with the finding of Chandankere et 
al. (2013). These tests showed BS's promising application in environment where extreme conditions of temperature, alkalinity and salt exist.

\subsection{Effect of surfactants on crude oil solubilization}

Water solubility enhancement of crude oil was evaluated by BS, SDS, LAS, Brij 30 and Tween 80 solutions at different concentrations ( 0.1 times, 0.2 times, 0.5 times, 1 times and 2 times of CMC). Results were shown in Fig.2, therein apparent solubility of crude oil was observed as a function of surfactant concentration. All the surfactants exhibited solubilization capacity in a concentration-dependent manner. When the surfactant concentration increased, the apparent solubility of crude oil increased. The solubilizing trend were different below and above the CMC concentration. The slope of the line changed abruptly in the middle and the inflection point was determined as the CMC of each surfactant, which was in consistent with findings of Chun et al.(2002). When surfactant concentration was below the CMC, the apparent solubility of crude oil increased slowly, which seemed negligible (Salager et al., 2013). As the BS concentration increased from 0 to $1 \mathrm{CMC}$, apparent solubility of crude oil in water just increased from $5.98 \mathrm{mg} / \mathrm{l}$ to $9.0 \mathrm{mg} / \mathrm{l}$, as for strain Brij 30, it was from $5.98 \mathrm{mg} / \mathrm{l}$ to $9.37 \mathrm{mg} / \mathrm{l}$. With regard to LAS, which showed the best performance, and the enhancement was from $5.98 \mathrm{mg} / \mathrm{l}$ to $11.84 \mathrm{mg} / \mathrm{l}$. However, when surfactants supplemented at concentrations above the CMC, the solubility enhancement of crude oil seemed more obvious, this may due to the formation of micelles at concentrations higher than CMC. Crude oil could dissolve in the micelle core, which is composed of the hydrophobic end of surfactant molecules. Within concentrations tested in our research, the extent of solubility enhancements at surfactant concentrations above their CMC followed the order: LAS $>$ Tween $80>\mathrm{BS}>\mathrm{SDS}>\mathrm{Brij} 30$. At $2 \mathrm{CMC}$ concentration of surfactants, the apparent solubility of crude oil 
for LAS, Tween 80, BS, SDS and Brij 30 was $29.10 \mathrm{mg} / \mathrm{l}, 26.32 \mathrm{mg} / \mathrm{l}, 22.01 \mathrm{mg} / \mathrm{l}, 18.31 \mathrm{mg} / \mathrm{l}$ and $17.08 \mathrm{mg} / \mathrm{l}$, respectively. Bordoloi and Konwar(2009) reported the biosurfactant (at the concentration of $500 \mathrm{mg} / \mathrm{l}$ ) from strain MTCC8165 had a more solubilization of crude oil compared with the control.

Even though the apparent solubility of crude oil was $29.10 \mathrm{mg} / \mathrm{l}$ with adding LAS of 2 CMC concentration, it seemed insignificant to the crude oil biodegradation. However, during the experiment process, surfactants could emulsify crude oil into tiny droplets with a few hours. The emulsification effect could also emerge at all 0.1 CMC concentrations. Tiny oil droplets suspended in the whole solution, thus the opportunity greatly increased for bacterial cells to contact with the hydrocarbon. Formation of tiny oil droplets facilitated the uptake of the substrate by organisms. It suggests that the increase of the crude oil bioavailability mainly seem due to the emulsification effect, other than solubilization in crude oil biodegradation system with surfactants.

\subsection{Effect of surfactants on cell surface hydrophobicity}

Cell surface hydrophobicity of microorganisms can be altered by adding surfactants due to the adsorption of surfactants on microorganism cells. Certain proteins and lipids present in cell walls are responsible for the hydrophobicity of microorganisms. Addition of surfactants is likely to cause phenotypic changes of microbial surface during growth (Hancock, 1991), thus resulted in the CSH change. Effect of five surfactants on CSH of the microbial community was investigated and shown in Fig.3. As observed in Fig.3A, the tested surfactants affected the cell surface differently. All surfactants at each concentration lowered the CSH of microorganisms. The CSH influence on microbial community by surfactants seemed type and concentration dependent. Generally, hydrophobicity would decrease with surfactants addition in contrast with observations 
by Kaczorek et al. (2010).

Fig.3B showed the combined effects of surfactants and crude oil on cell surface hydrophobicity, which was different with the only surfactant existed (Fig.3A). BS at a low concentration caused a significant increase of CSH (Fig 3B). While the concentration exceeded 1CMC, the CSH would decrease. For Tween 80, the similar trend was observed, and the high concentration of 4 CMC decreased the CSH. For SDS, the effect on CSH was not obvious. However, Brij 30 and LAS had a negative effect on hydrophobicity.

Change of cell surface hydrophobicity was a complex process, relatied to the type and concentration of surfactants and carbon sources. Gorna et al.(2011) reported that the increase of CSH followed the order: a dodecane and hexadecane mixtures > diesel oil > glucose. Sakthipriya et al. (2015) reported that CSH was higher for the waxy crude oil than model crude oil (mixture of the six long chain paraffins), which might be due to less hydrophobic, short chain paraffins present in the waxy crude oil. Different surfactant interacted with the cell surface differently. Al-Tahhan et al.(2000) reported that interaction of rhamnolipides with cell surfaces of Pseudomonas caused a loss of lipopolysaccharide (LPS), which was an important hydrophilic component in cell surfaces, and increased the CSH. While natural surfactant saponins were built into the membrane lipophilic part, it would increase membrane permeability (Skłodowskiej-Curie, 2006). It seemed that surfactants could decrease hydrophobicity for those with high cell surface hydrophobicity and increase hydrophobicity for those hydrophilic ones (Owsianiak et al., 2009; Zhao et al., 2011).

\subsection{Growth inhibition of surfactants on microorganisms}

Power-time curves of microbial growth at different surfactant concentrations were shown in Fig.4 (A for SDS, B for LAS, C for Brij 30, D for Tween 80 and E for BS). The figure in small 
box located in the upper right corner was an enlarged schematic view of figures in the dotted line. For all surfactants, it was apparent that the increase of surfactant concentrations could prolong lag phase and gradually reduce peak height. The inhibition effect of surfactants on microorganisms was greater with the concentration increase. The inhibition extent was different for each surfactant. Microorganisms could grow well at different SDS concentrations (Fig.4A), and slight inhibition occurred at high SDS dose. Fig. 4B, 4C revealed that microorganisms could not grow mostly at $1 \mathrm{CMC}$ and $2 \mathrm{CMC}$ concentrations of LAS and Brij 30. For Tween 80 and BS, 1CMC concentration also strongly inhibited the growth of microorganisms (Fig. 4D, 4E). Surprisingly, the inhibition effect for Tween 80 and BS at $2 \mathrm{CMC}$ concentration was smaller than at $1 \mathrm{CMC}$ concentration.

The produced total heat $\left(Q_{\text {total }}\right)$, maximum power evolution $\left(P_{\max }\right)$, time to reach the $P_{\max }\left(t_{\max }\right)$ and microbial growth rate constant $(k)$ were obtained from power curves listed in Table 1. $Q_{\text {total }}$ was obtained with integration of each curve from the beginning to the end, while $P_{\max }$ and $t_{\max }$ could be obtained directly from each power curve (Yu et al., 2013). With the equation: $\ln P_{\mathrm{t}}=\ln P_{0}$ $+k \cdot t$, the constant $k$ could be calculated from the slope of semi-logarithm of exponential phase (Yao et al., 2008). $Q_{\text {total }}$ is the heat sum of catabolic process and reflects microbial activities. The relationship between $Q_{\text {total }}$ and surfactant concentrations for microorganisms were shown in Table 1. Generally, the total heat would decrease, when the surfactant concentration increased. The same trend was found with $P_{\max }$. This phenomenon showed surfactant toxicity to microbial community will increase with higher dose of each surfactant. This could be confirmed from the extended $t_{\max }$. The highest growth rate $k$ was obtained for control in each system, and $k$ value gradually decreased with the increasing surfactant dose. 
Table 1 Thermal parameters obtained from microcalorimetric experiments of microbial community at $28{ }^{0} \mathrm{C}$

\begin{tabular}{|c|c|c|c|c|c|c|}
\hline Surfactant & $C^{\mathrm{a}}$ & $Q_{\text {total }}^{\mathrm{b}}(\mathrm{J})$ & $P_{\max }{ }^{\mathrm{c}}(\mu \mathrm{W})$ & $t_{\max }{ }^{\mathrm{d}}(\mathrm{h})$ & $k^{\mathrm{e}}\left(\mathrm{h}^{-1}\right)$ & $r^{\mathrm{f}}$ \\
\hline \multirow[t]{6}{*}{ SDS } & 0 & 210.2 & 441.3 & 21.2 & $0.330 \pm 0.001436$ & 0.9981 \\
\hline & $0.1 \mathrm{cmc}$ & 122.5 & 383.2 & 16.5 & $0.291 \pm 0.00561$ & 0.9988 \\
\hline & $0.2 \mathrm{cmc}$ & 217.8 & 301.5 & 26.6 & $0.217 \pm 0.000639$ & 0.9996 \\
\hline & $0.5 \mathrm{cmc}$ & 194.0 & 277.8 & 46.6 & $0.0560 \pm 0.0000751$ & 0.9996 \\
\hline & $1 \mathrm{cmc}$ & 141.2 & 253.5 & 49.6 & $0.108 \pm 0.00153$ & 0.9986 \\
\hline & $2 \mathrm{cmc}$ & 116.6 & 242.8 & 53.4 & $0.0702 \pm 0.00362$ & 0.9977 \\
\hline \multirow[t]{6}{*}{ LAS } & 0 & 176.2 & 516.9 & 9.70 & $0.471 \pm 0.00285$ & 0.9908 \\
\hline & $0.1 \mathrm{cmc}$ & 203.5 & 409.2 & 13.5 & $0.357 \pm 0.00440$ & 0.9886 \\
\hline & $0.2 \mathrm{cmc}$ & 57.5 & 387.3 & 15.8 & $0.373 \pm 0.00675$ & 0.9909 \\
\hline & $0.5 \mathrm{cmc}$ & 47.2 & 125.2 & 19.2 & $0.0757 \pm 0.00007$ & 0.9959 \\
\hline & $1 \mathrm{cmc}$ & 3.9 & 50.2 & 20.8 & $0.578 \pm 0.00864$ & 0.9930 \\
\hline & $2 \mathrm{cmc}$ & 6.0 & 59.6 & 19.6 & $0.335 \pm 0.00641$ & 0.9821 \\
\hline \multirow[t]{6}{*}{ Brij30 } & 0 & 176.0 & 516.9 & 9.70 & $0.501 \pm 0.006401$ & 0.9902 \\
\hline & $0.1 \mathrm{cmc}$ & 227.0 & 516.6 & 10.2 & $0.397 \pm 0.00186$ & 0.9939 \\
\hline & $0.2 \mathrm{cmc}$ & 217.1 & 487.1 & 11.5 & $0.350 \pm 0.00220$ & 0.9885 \\
\hline & $0.5 \mathrm{cmc}$ & 200.4 & 400.1 & 12.4 & $0.343 \pm 0.00493$ & 0.9913 \\
\hline & $1 \mathrm{cmc}$ & 5.7 & 355.2 & 13.0 & $0.619 \pm 0.00711$ & 0.9880 \\
\hline & $2 \mathrm{cmc}$ & 9.2 & 387.5 & 13.2 & $0.444 \pm 0.00408$ & 0.9944 \\
\hline \multirow[t]{6}{*}{ Tween 80} & 0 & 210.2 & 441.3 & 21.2 & $0.309 \pm 0.000983$ & 0.9995 \\
\hline & $0.1 \mathrm{cmc}$ & 203.0 & 369.8 & 22.2 & $0.297 \pm 0.000605$ & 0.9998 \\
\hline & $0.2 \mathrm{cmc}$ & 172.9 & 287.8 & 29.3 & $0.238 \pm 0.00104$ & 0.9951 \\
\hline & $0.5 \mathrm{cmc}$ & 213.6 & 263.4 & 44.2 & $0.185 \pm 0.00702$ & 0.9803 \\
\hline & $1 \mathrm{cmc}$ & 4.1 & 158.7 & 13.1 & $0.391 \pm 0.00464$ & 0.9971 \\
\hline & $2 \mathrm{cmc}$ & 199.3 & 228.5 & 46.5 & $0.172 \pm 0.00119$ & 0.9974 \\
\hline \multirow[t]{6}{*}{ Biosurfactant } & 0 & 214.5 & 507.8 & 14.0 & $0.477 \pm 0.00246$ & 0.9926 \\
\hline & $0.1 \mathrm{cmc}$ & 213.7 & 492.1 & 14.0 & $0.456 \pm 0.00214$ & 0.9974 \\
\hline & $0.2 \mathrm{cmc}$ & 218.9 & 486.3 & 14.8 & $0.381 \pm 0.000474$ & 0.9999 \\
\hline & $0.5 \mathrm{cmc}$ & 188.8 & 470.9 & 15.2 & $0.388 \pm 0.00337$ & 0.9957 \\
\hline & $1 \mathrm{cmc}$ & 7.8 & 312.1 & 14.9 & $0.293 \pm 0.000513$ & 0.9980 \\
\hline & $2 \mathrm{cmc}$ & 46.7 & 333.0 & 17.2 & $0.283 \pm 0.00144$ & 0.9945 \\
\hline
\end{tabular}

${ }^{\mathrm{a} C o n c e n t r a t i o n ~ o f ~ e a c h ~ s u r f a c t a n t ~}$

${ }^{b}$ Total thermal effect of samples above the value $(\mathrm{P}=0 \mu \mathrm{W})$ of thermal power axis

${ }^{\mathrm{c}} \mathrm{Highest}$ thermal power

${ }^{\mathrm{d}}$ Time to reach the highest peak

${ }^{\mathrm{e}}$ Microbial growth rate constant $(\mathrm{mean} \pm \mathrm{SD})$

${ }^{\mathrm{f}}$ Correlation coefficient by calculating the microbial growth rate constant

Considering CMC values, the toxicity of surfactants to microorganisms followed the order:

Brij30 > BS > Tween $80>$ LAS > SDS. It was well-known that surfactants are toxic to bacteria

(Volkering et al., 1995). Sajna et al.(2015) reported that most biosurfactants exhibited toxicity at 
higher concentrations, which influenced cell surface properties and metabolic pathways, then resulted in the biomass decrease.

\subsection{Effect of surfactants on crude oil biodegradation}

Effect of five surfactants on crude oil biodegradation were studied and shown in Table 2.

Gravimetric analysis showed the percentage of crude oil biodegradation without surfactant was $50.5 \pm 2.80$ with respect to the abiotic control, which was taken as $100 \%$. The loss of crude oil caused by non-biological process was $6.55 \%$ determined by the control experiment. All values in Table 2 had been subtracted the abiotic loss. Slight enhancement of crude oil biodegradation with SDS was observed. Highest degradation of crude oil appeared when SDS concentration was 1 CMC, while biodegradation rate slightly declined at 2 CMC concentration. And lower LAS concentration could enhance biodegradation processes, but higher concentration showed negative effects. Meanwhile, all concentrations for Brij 30 had a negative effect on the biodegradation. The biodegradation rate decreased with increased concentrations. Tween 80 did not cause a big impact on the biodegradation process, but the degradation was suppressed at $1 \mathrm{CMC}$ concentration. Addition of BS slightly facilitated the biodegradation process at low concentrations of $0.1 \mathrm{CMC}$, 0.2 CMC and 0.5 CMC. However, the inhibitory effect appeared at higher concentrations due to its antibacterial activity.

Table 2 The influence of surfactant on crude oil biodegradation

\begin{tabular}{ccccccc}
\hline \multirow{2}{*}{$\begin{array}{c}\text { Surfactant } \\
\text { concentration }\end{array}$} & SDS & LAS & Brij 30 & Tween 80 & Biosurfactant & Without surfactant \\
\cline { 2 - 7 } & $51.5 \pm 1.70$ & $52.6 \pm 0.60$ & $49.2 \pm 1.25$ & $50.7 \pm 1.35$ & $52.6 \pm 1.60$ & \\
\hline $0.1 \mathrm{cmc}$ & $53.9 \pm 1.13$ & $50.9 \pm 2.40$ & $49.0 \pm 0.50$ & $48.9 \pm 0.42$ & $53.6 \pm 2.41$ & $50.5 \pm 2.80$ \\
$0.2 \mathrm{cmc}$ & $50.1 \pm 1.54$ & $43.2 \pm 1.21$ & $47.3 \pm 1.20$ & $48.0 \pm 1.17$ & $50.6 \pm 0.58$ & \\
$0.5 \mathrm{cmc}$ & $54.4 \pm 1.98$ & $31.0 \pm 3.05$ & $32.2 \pm 2.10$ & $40.0 \pm 0.40$ & $41.3 \pm 2.30$ & \\
$1 \mathrm{cmc}$ & $51.1 \pm 0.65$ & $28.9 \pm 1.10$ & $37.0 \pm 1.53$ & $49.4 \pm 4.50$ & $45.2 \pm 2.82$ & \\
$2 \mathrm{cmc}$ & & & & & \\
\hline
\end{tabular}

${ }^{\mathrm{a} C}$ Compared with the abiotic controls at the end of the experiment 
Crude oil biodegradation is a complex process involved interactions among bacteria, surfactants and carbon sources. Surfactants exhibited positive or negative effects in bioremediation processes (Kaczorek et al., 2015; Singh et al., 2007), and this was consistent with findings in this study. For some surfactants (SDS, LAS, BS), opportune dose could improve the biodegradation rate due to the increasing CSH value or the solubilization effect. However, surfactants at high concentrations might inhibit the degradation due to biologcial toxicity or the micelle formation. Hydrocarbon dissolved in micelles might obstruct its contact with organisms. Therefore, it is very important to select surfactants before their application on the biodegradation of hydrophobic organic pollutants.

On the basis of those results, it found that surfactants could promote or inhibit the crude oil biodegradation depending on their types and concentrations. In spite of the solubilization and emulsification effect caused by surfactants, the overall effect on the biodegradation rate could be negative, reflecting complexities of the degradation process. In addition, there seemed no obvious relationship between the $\mathrm{CSH}$ value of microorganisms and the biodegradation. Chakraborty et al.(2010) reported that changes in cellular properties may not be necessarily associated with the ability to utilize certain carbon sources, and therefore may not be easily correlated with bioremediation efficiency. Considering the antimicrobial activity, surfactants should be used in the proper concentration to achieve the best result. However, results in this study showed that there wasn't great promotion of crude oil biodegradation achieved through surfactant supplementations. The best result in this study showed only $4 \%$ enhancement compared with that without surfactants. Taking cost into account, the addition of surfactants to the biodegradation system didn't seem so necessary. Kaczorek et al.(2015) also reported that the addition of surfactants became unnecessary for microorganisms with a high potential of hydrocarbon removal. During the cultivation process, 
crude oil in flasks without surfactants dispersed into tiny oil droplets, and surface tension of the culture medium reduced to $47.1 \mathrm{mN} / \mathrm{m}$, indicating secretions of surface active agents were produced by microorganisms. From previous studies, surface active agents were usually biosurfactants, organic acids and biopolymers (Youssef et al., 2009). The time was shorter for crude oil emulsification in flasks supplemented with surfactants, usually within a few hours, thus the adaptation period of microorganisms could be greatly reduced.

The residual oil extracted was analyzed quantitatively using GC-MS analysis. The total ion chromatogram (TIC) of oil samples were shown in Fig.5. The crude oil was highly degraded and completely depleted of n-alkanes (Fig.5A). Fig.5B showed the reduction of light components (short-chain alkanes, naphthalenes et.al.) in oil due to evaporative losses. Varjani et al. (2015) revealed lower alkanes of $\mathrm{C}_{8}-\mathrm{C}_{10}$ in crude oil were depleted $100 \%$ after 25 days incubation in control flasks, which indicated abiotic/physical factors might result in the removal of these components. Fig 5C showed crude oil had been strongly degraded, which could be concluded from the decreased peaks. The finding by Varjani et al. (2015) showed $83.49 \%$ of crude oil biodegradation was conducted by HUBC (Hydrocarbon utilizing bacterial consortium) with gas chromatographic analysis. And little difference between Fig 5C and 5D was observed. In order to investigate changes in the distribution of petroleum components, semi-quantitative analysis was applied as described by Cai et al.(2013). N-alkanes in the original crude oil was severely deficient. Regarding the aromatic degradation, eight targeted PAHs were selected with ring numbers ranging from 2-4. The degradation rate of the selected PAHs ranged from $31.1 \%$ to $92.8 \%$ (data not shown). Lighter compounds were badly degraded, while the higher molecular-weighted and more alkylated compounds were slightly degraded. By adding surfactants to the degradation system, 
PAHs with complex structures were degraded successfully.

\section{Conclusions}

Five surfactants were used to evaluate their effects on crude oil biodegradation. It found that surfactants could improve the apparent solubility of crude oil in water and emulsify crude oil into tiny oil droplets within a few hours. Surfactants could change CSH of microorganisms based on their types and concentrations. Except SDS, all surfactants showed toxicity to microorganisms at high concentrations. Microbiota in the biodegradation experiment showed a high potential of petroleum aerobic degradation in a short time, and about $50.5 \%$ of petroleum degraded in ten days. Biosurfactant, SDS and LAS at low concentrations could slightly promote the biodegradation process, but inhibitory effect at high concentrations appeared due to their antibacterial activity. However, the increased uptake of crude oil and its components on the surfactant addition was not so significant. These results indicate that a comprehensive research of surfactants influencing the microorganism and its biodegradation should be done before their applications.

\section{Acknowledgments}

This work is supported in part by grants from the International Joint Key Project from Chinese Ministry of Science and Technology (2010DFB23160), Key project from National Science Foundation of China(41430106), National Natural Science Foundation of China (41273092), Public welfare project of Chinese Ministry of Environmental Protection (201409042), Overseas, Hong Kong and Macau Young Scholars Collaborative Research Fund (41328005), and Key Project Supported by the Natural Science Foundation of the Higher Education Institutions of Anhui Province (KJ2016A432). We gratefully acknowledge all the supports provided. 


\section{References}

Abdel-Mawgoud, A. M., et al., 2008. Characterization of surfactin produced by Bacillus subtilis isolate BS5. Appl. Biochem. Biotech. 150, 289-303.

Abouseoud, M., et al., 2008. Evaluation of different carbon and nitrogen sources in production of biosurfactant by Pseudomonas fluorescens. Desalination. 223, 143-151.

Al-Tahhan, R. A., et al., 2000. Rhamnolipid-induced removal of lipopolysaccharide from Pseudomonas aeruginosa: effect on cell surface properties and interaction with hydrophobic substrates. Appl. Environ. Microb. 66, 3262-3268.

Bao, M.-t., et al., 2012. Biodegradation of crude oil using an efficient microbial consortium in a simulated marine environment. Mar. Pollut. Bull. 64, 1177-1185.

Benincasa, M., et al., Rhamnolipid surfactants: alternative substrates, new strategies. Biosurfactants. Springer, 2010, pp. 170-184.

Bordoloi, N., Konwar, B., 2009. Bacterial biosurfactant in enhancing solubility and metabolism of petroleum hydrocarbons. J. Hazard. Mater. 170, 495-505.

Brito, E. M. S., 2006. Characterization of hydrocarbonoclastic bacterial communities from mangrove sediments in Guanabara Bay, Brazil. Brazil Res Microbiol. 157, 752-762.

Cai, M., et al., 2015. Potential for aerobic and methanogenic oil biodegradation in a water flooded oil field (Dagang oil field). Fuel. 141, 143-153.

Cai, M., et al., 2013. Aerobic biodegradation process of petroleum and pathway of main compounds in water flooding well of Dagang oil field. Bioresource.Technol. 144, 100-106.

Chakraborty, S., et al., 2010. Surface hydrophobicity of petroleum hydrocarbon degrading Burkholderia strains and their interactions with NAPLs and surfaces. Colloid. Surface. B. 78, 
101-108.

Chandankere, R., et al., 2013. An efficient biosurfactant-producing and crude-oil emulsifying bacterium Bacillus methylotrophicus USTBa isolated from petroleum reservoir. Biochem. Eng. J. 74, 46-53.

Chrzanowski, Ł., et al., 2011. Interactions between rhamnolipid biosurfactants and toxic chlorinated phenols enhance biodegradation of a model hydrocarbon-rich effluent. Int. Biodeter. Biodegr. $65,605-611$

Chun, C. L., et al., 2002. Solubilization of PAH mixtures by three different anionic surfactants. Environ. Pollut. 118, 307-313.

Critter, S. A., et al., 2001. Calorimetry versus respirometry for the monitoring of microbial activity in a tropical soil. Appl. Soil. Ecol. 18, 217-227.

Díaz, M. P., et al., 2000. Isolation and characterization of novel hydrocarbon-degrading euryhaline consortia from crude oil and mangrove sediments. Mar. Biotechnol. 2, 522-532.

El-Tarrs, A. E., et al., 2012. In vitro screening for oil degrading bacteria and evaluation of their biodegradation potential for hydrocarbon. Afr. J. Microbiol. Res. 6, 7534-7544.

Ferradji, F. Z., et al., 2014. Naphthalene and crude oil degradation by biosurfactant producing Streptomyces spp. isolated from Mitidja plain soil (North of Algeria). Int. Biodeter. Biodegr. $86,300-308$.

Górna, H., et al., 2011. Differences and dynamic changes in the cell surface properties of three Pseudomonas aeruginosa strains isolated from petroleum-polluted soil as a response to various carbon sources and the external addition of rhamnolipids. Bioresource.Technol. 102, 3028-3033. 
Ghribi, D., et al., 2012. Investigation of antimicrobial activity and statistical optimization of Bacillus subtilis SPB1 biosurfactant production in solid-state fermentation. Biomed. Res. Int. 2012.

Greenwood, P. F., et al., 2009. Hydrocarbon biodegradation and soil microbial community response to repeated oil exposure. Org. Geochem. 40, 293-300.

Hancock, I. C., 1991. Microbial cell surface architecture. Microbial cell surface analysis. 23-59.

Hii, Y. S., et al., 2009. Biodegradation of Tapis blended crude oil in marine sediment by a consortium of symbiotic bacteria. Int. Biodeter. Biodegr. 63, 142-150.

Janbandhu, A., Fulekar, M., 2011. Biodegradation of phenanthrene using adapted microbial consortium isolated from petrochemical contaminated environment. J. Hazard. Mater. 187, 333-340.

Kaczorek, E., et al., 2015. Effect of Glucopon 215 on cell surface properties of Pseudomonas stutzeri and diesel oil biodegradation. Int. Biodeter. Biodegr. 104, 129-135.

Kaczorek, E., et al., 2010. The influence of surfactants on cell surface properties of Aeromonas hydrophila during diesel oil biodegradation. Colloid. Surface. B. 81, 363-368.

Kumar, A. G., et al., 2014. Biodegradation of complex hydrocarbons in spent engine oil by novel bacterial consortium isolated from deep sea sediment. Bioresource.Technol.170, 556-564.

Liu, H., et al., 2014. Isolation and characterization of crude-oil-degrading bacteria from oil-water mixture in Dagang oilfield, China. Int. Biodeter. Biodegr. 87, 52-59.

Luning Prak, D. J., et al., 2000. Solubilization rates of n-alkanes in micellar solutions of nonionic surfactants. Environ. Sci. Technol. 34, 476-482.

Megharaj, M., et al., 2011. Bioremediation approaches for organic pollutants: a critical perspective. Environ. Int. 37, 1362-1375.

Millioli, V., et al., 2009. Bioremediation of crude oil-bearing soil: evaluating the effect of rhamnolipid 
addition to soil toxicity and to crude oil biodegradation efficiency. Global NestJ. 11, 181-188.

Molina, M. C., et al., 2009. Isolation and genetic identification of PAH degrading bacteria from a microbial consortium. Biodegradation. 20, 789-800.

Mnif, S., et al., 2014. Biodegradative potential and characterization of a novel aromatic-degrading bacterium isolated from a geothermal oil field under saline and thermophilic conditions. Int. Biodeter. Biodegr. 86, 258-264.

Mukherjee, A. K., 2007. Potential application of cyclic lipopeptide biosurfactants produced by Bacillus subtilis strains in laundry detergent formulations. LETT Appl. Microbiol. 45, 330-335.

Mulligan, C. N., 2005. Environmental applications for biosurfactants. Environ. Pollut. 133, 183-198.

Najafi, A., et al., 2010. Enhancing biosurfactant production from an indigenous strain of Bacillus mycoides by optimizing the growth conditions using a response surface methodology. Chem.Eng. J. 163, 188-194.

Obuekwe, C. O., et al., 2009. Hydrocarbon degradation in relation to cell-surface hydrophobicity among bacterial hydrocarbon degraders from petroleum-contaminated Kuwait desert environment. Int. Biodeter. Biodegr. 63, 273-279.

Owsianiak, M., et al., 2009. Biodegradation and surfactant-mediated biodegradation of diesel fuel by 218 microbial consortia are not correlated to cell surface hydrophobicity. Appl. Microbiol. Biot. 84, 545-553.

Pathak, K. V., Keharia, H., 2013. Application of extracellular lipopeptide biosurfactant produced by endophytic Bacillus subtilis $\mathrm{K} 1$ isolated from aerial roots of banyan (Ficus benghalensis) in microbially enhanced oil recovery (MEOR). Biotech. 4, 41-48.

Paria, S., 2008. Surfactant-enhanced remediation of organic contaminated soil and water. Adv. Colloid. 
Interfac. 138, 24-58.

Prince, R. C., et al., 2013. The primary biodegradation of dispersed crude oil in the sea. Chemosphere. 90, 521-526.

Rosenberg, M., et al., 1980. Adherence of bacteria to hydrocarbons: a simple method for measuring cell-surface hydrophobicity. Fems. Microbiol. Lett. 9, 29-33.

Sajna, K. V., et al., 2015. Crude oil biodegradation aided by biosurfactants from Pseudozyma sp. NII 08165 or its culture broth. Bioresource.Technol. 191, 133-139.

Sakthipriya, N., et al., 2015. Action of biosurfactant producing thermophilic Bacillus subtilis on waxy crude oil and long chain paraffins. Int. Biodeter. Biodegr. 105, 168-177.

Salager, J.-L., et al., 2013. How to attain an ultralow interfacial tension and a three-phase behavior with a surfactant formulation for enhanced oil recovery: a review. Part 2. Performance improvement trends from Winsor's premise to currently proposed inter-and intra-molecular mixtures. J. Surfactants. Deterg. 16, 631-663.

Saul, D. J., et al., 2005. Hydrocarbon contamination changes the bacterial diversity of soil from around Scott Base, Antarctica. FEMS MicrobiolEcol. 53, 141-155.

Shokrollahzadeh, S., et al., 2008. Biodegradation Potential and Bacterial Diversity of a Petrochemical Wastewater Treatment Plant in Iran. Bioresour Technol. 99, 6127-33.

Singh, A., et al., 2007. Surfactants in microbiology and biotechnology: Part 2. Application aspects. Biotechnol. Adv. 25, 99-121.

Skłodowskiej-Curie, P. M., 2006. The ability of Candida maltosa for hydrocarbon and emulsified hydrocarbon degradation. Pol. J. Environ. Stud. 15, 47-51.

Thavasi, R., et al., 2011. Application of biosurfactant produced from peanut oil cake by Lactobacillus 
delbrueckii in biodegradation of crude oil. Bioresource.Technol. 102, 3366-3372.

Urum, K., Pekdemir, T., 2004. Evaluation of biosurfactants for crude oil contaminated soil washing. Chemosphere. 57, 1139-1150.

Varjani, S. J., et al., 2015. Synergistic ex-situ biodegradation of crude oil by halotolerant bacterial consortium of indigenous strains isolated from on shore sites of Gujarat, India. Int. Biodeter. Biodegr. 103, 116-124.

Volkering, F., et al., 1995. Influence of nonionic surfactants on bioavailability and biodegradation of polycyclic aromatic hydrocarbons. Appl. Environ. Microb. 61, 1699-1705.

Wang, F., et al., 2009. Microcalorimetric measurements of the microbial activities of single-and mixed-species with trivalent iron in soil. Ecotox. Environ. Safe. 72, 128-135.

Wang, Z., 2011. Bioavailability of organic compounds solubilized in nonionic surfactant micelles. Appl.Microbiol. Biot. 89, 523-534.

Yao, J., et al., 2008. Microcalorimetric study the toxic effect of hexavalent chromium on microbial activity of Wuhan brown sandy soil: an in vitro approach. Ecotox. Environ. Safe. 69, 289-295.

Youssef, N., et al., 2009. Microbial processes in oil fields: culprits, problems, and opportunities. Adv. Appl. Microbiol. 66, 141-251.

Yu, C., et al., 2013. Functional gene expression of oil-degrading bacteria resistant to hexadecane toxicity. Chemosphere. 93, 1424-1429.

Yu, H., et al., 2007. Enhanced desorption and biodegradation of phenanthrene in soil-water systems with the presence of anionic-nonionic mixed surfactants. J. Hazard. Mater. 142, 354-361.

Zhao, Z., et al., 2011. Effects of rhamnolipids on cell surface hydrophobicity of PAH degrading bacteria and the biodegradation of phenanthrene. Bioresource.Technol. 102, 3999-4007. 


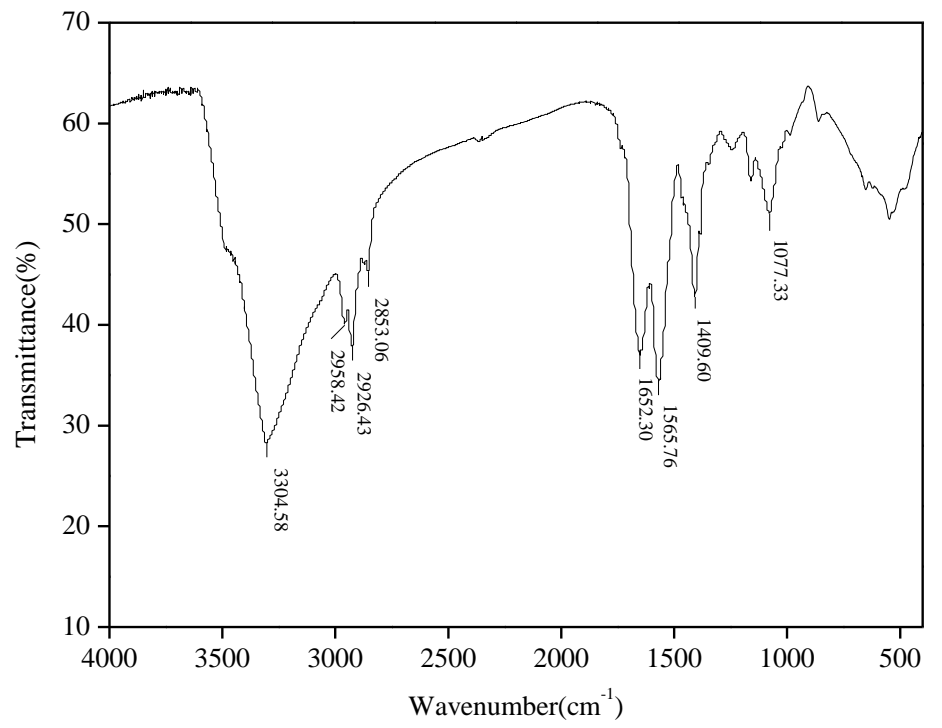

Fig.1. FT-IR spectrum of the biosurfactant produced by Bacillus subtilis strain WU-3.

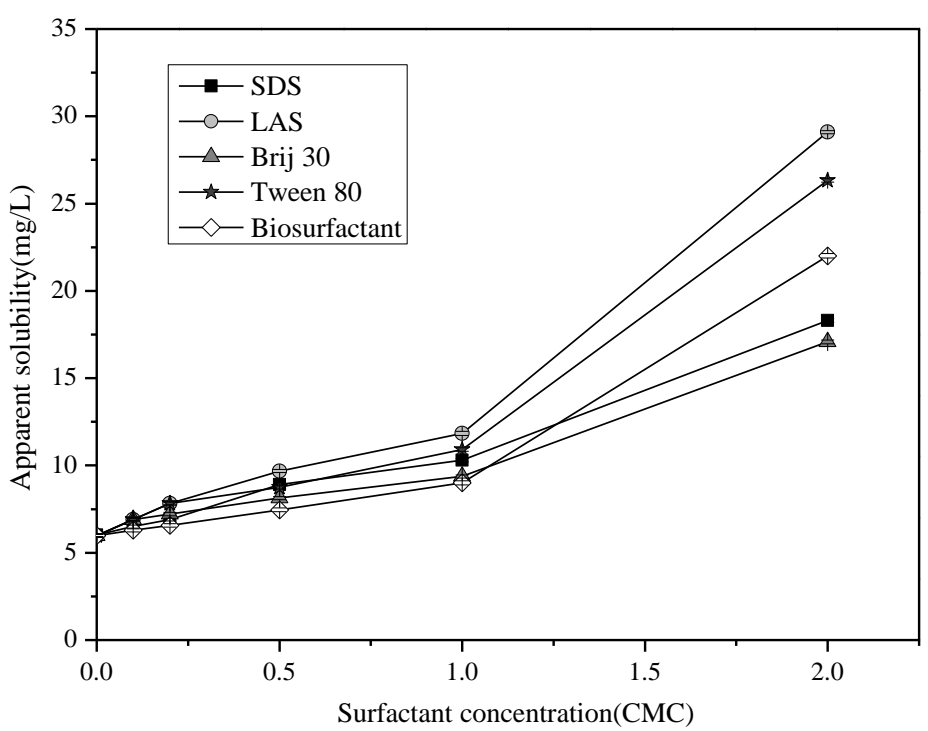

Fig.2. Effects of surfactant BS, SDS, LAS, Brij 30 and Tween 80 on crude oil solubilization, and those results were represented with mean \pm standard deviation in triplicate.
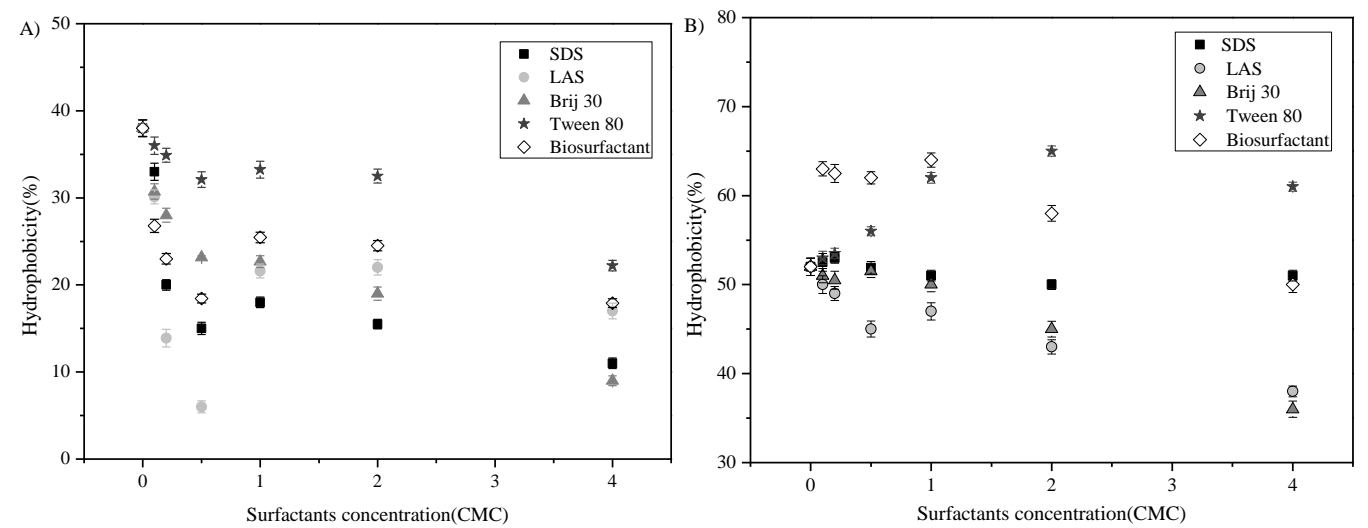

Fig.3. Effect of surfactant quantity on cell surface hydrophobicity; hydrophobicity measured by the MATH method; in surfactant system A), in surfactant-crude oil system B). Results represented with mean \pm standard deviation in triplicate. 

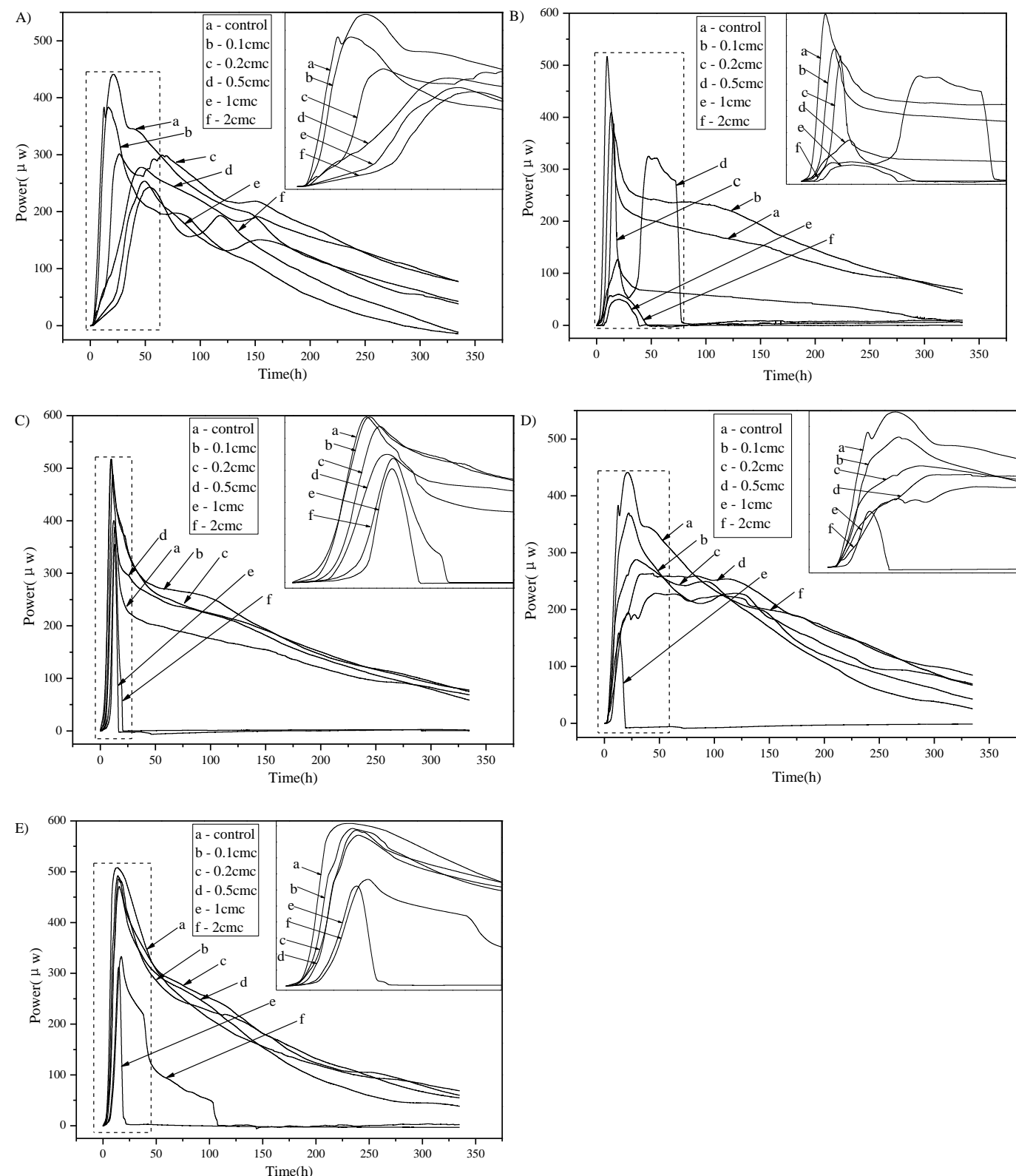

Fig.4. Metabolic power-time curves of microbial communities growing in LB medium containing various concentrations of surfactants obtained by microcalorimetric measurement. A) SDS, B) LAS, C) Brij 30, D), Tween 80, and E) BS. 


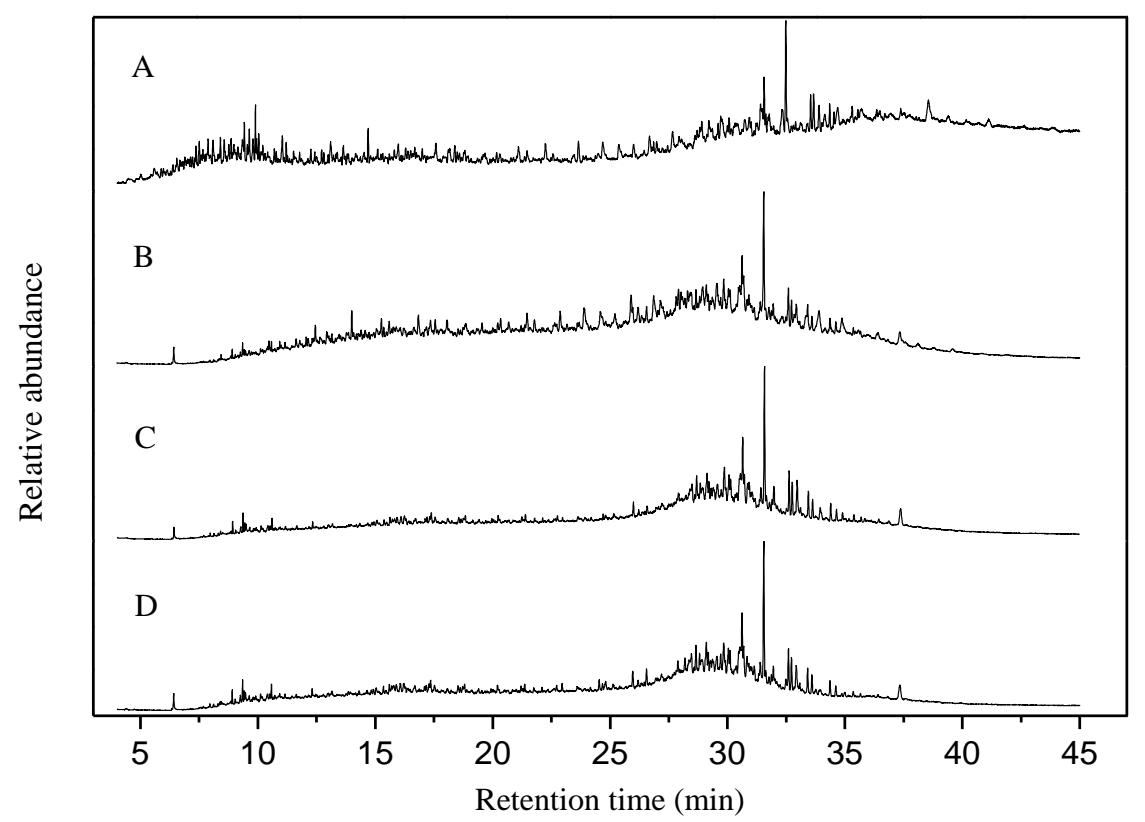

Fig.5The total ion chromatogram (TIC) of the oil before and after degradation (A: the original oil; B: oil of abiotic control; C: residual oil of biotic degradation system; D: residual of biotic degradation system supplemented with LAS at $0.1 \mathrm{CMC}$ concentration) 